\title{
Awareness and Perception of the Researchers of Philippine Rice Research Institute in Nueva Ecija in the Philippines on the Implementation of New Policy on Research and Publication
}

\author{
Abegail T. Donayre1,2, Rosemarie R. Casimiro², Elizabeth P. Molina1,2 \\ ${ }^{1}$ Philippine Rice Research Institute, Maligaya, Science City of Munoz, Nueva Ecija, Philippines \\ ${ }^{2}$ Department of Public Administration, Nueva Ecija University of Science and Technology, Cabanatuan City, Nueva Ecija, \\ Philippines \\ Email: casimirorm11@gmail.com
}

How to cite this paper: Donayre, A.T., Casimiro, R.R. and Molina, E.P. (2020) Awareness and Perception of the Researchers of Philippine Rice Research Institute in Nueva Ecija in the Philippines on the Implementation of New Policy on Research and Publication. Open Access Library Journal, 7: e6077.

https://doi.org/10.4236/oalib.1106077

Received: January 14, 2020

Accepted: February 17, 2020

Published: February 21, 2020

Copyright $\odot 2020$ by author(s) and Open Access Library Inc.

This work is licensed under the Creative Commons Attribution International License (CC BY 4.0).

http://creativecommons.org/licenses/by/4.0/

\section{(c) (i) Open Access}

\begin{abstract}
Research plays an important role in the generation of new knowledge and in the dissemination of valuable information. Academicians and scientists across the nations use research to prove or disprove both common knowledge and emerging concepts in various fields of discipline. For the information to be more scholarly and for it to gain wider readership, completed research works are submitted for peer-review and publication in journals. In the field of public administration, researches serve as bases for policy reforms and in the management of an organization's public affairs. The academes, research institutions, and private companies also consider research output and publication as tools to assess the performance of their staff. To further simplify the process and encourage compliance, the Philippine Rice Research Institute (PhilRice) introduced in 2012 a policy reform on research publication through the issuance of administrative orders and memorandum orders. These issuances in PhilRice encouraged the researchers of this study to determine the level of awareness and perception of the PhilRice researchers on the new policies. Survey questionnaires are distributed to 37 staff assigned in the different research divisions of PhilRice. Analysis of data suggests that ninety-seven percent is aware of the policy on publication since it was disseminated through various media (emails, meetings, and colleagues). While all of the respondents support the policy, ninety-two percent suggests that for it to be fully-realized, certain provisions must be amended. The results of the study could be a potential source of information for administrators and decision-makers on how research can be used to enhance individual and institu-
\end{abstract}


tional transparency and accountability. It could also serve as a basis for the further improvement of policies, and lastly, as a guide for future researchers who are interested to pursue similar study on a different setting.

\section{Subject Areas}

Sociology

\section{Keywords}

Accountability, Awareness, PhilRice, Publication, Transparency, Philippines

\section{Introduction}

Research plays an important role in the generation of new knowledge and in the dissemination of valuable information [1]. Academicians and scientists across nations use research to prove or disprove both common knowledge and emerging concepts in various fields of discipline [2]. For the information to be more scholarly and for it to gain wider readership, completed research works are submitted for peer-review and publication in journals. The journals serve as online platforms where scholarly and scientific papers are stored and made accessible to the public [3] [4]. Some are openly accessed in which full text can be viewed and downloaded free of charge. Others, especially those published in top-tier journals require payment before the contents can be accessed. In the field of public administration, researches serve as bases for policy reforms and in the management of an organization's public affairs [1]. The academes, research institutions, and private companies also consider research output and publication as tools to assess the performance of their staff. Scientific writing is very important especially in documenting and communicating ideas, activities, and findings to others. It can take many forms like lab notebooks, project reports, academic journals or articles in scientific magazines [5].

The very purpose of doing research and publishing the same is to contribute to the body of knowledge in the different fields [1]. Research helps researchers gain fresh and novel ideas, replicate the processes undertaken using a new locale, and be guided by theories and scientific models [2]. For many years, it has been one of the most commonly used tools in the academes, research institutions, and private companies to evaluate staff performance [6]. Authorship of scholarly articles offers opportunities for the staff to be known as experts and knowledge contributors in a particular field [7]. Moreover, having surpassed the rigorous process of peer-review journals gives pride to the author and gives credit also to the author and his/her country and institution.

The Philippine Rice Research Institute (PhilRice) is a government corporate entity under the Department of Agriculture (DAR). It was created on November 5, 1985 through Executive Order No. 1061 to help develop high-yielding and cost-reducing technologies so farmers can produce enough rice for all Filipinos 
[8]. Since its creation, PhilRice has helped with the rice farmers' struggle for self-sufficiency. The Institute made it possible through research and development works initiated from both the central and branch stations.

In 2006, PhilRice Central Experiment Station received three management system certifications. These are the ISO 9001 (Quality), ISO 14001 (Environmental), OHSAS 18001 (Occupational Health and Safety Assessment Series) that unify the organization, resources, processes, and practices components into one system. All those additional standards implemented in the institution achieve the organization's purpose and mission. In order to have an equal distribution of workload and to ensure the efficient delivery of desired outcomes in research and development, Administrative Order No. 2012-09, otherwise known as the "Guidelines for Crediting the Performance of PhilRice Senior R \& D Staff Members" was issued. The AO No. 2012-09 emphasized continuous effort of PhilRice to improve the functionality of its systems and to maintain its track record of excellence in research and technology-based services. The recent guidelines also recommend the use of the following parameters for the evaluation of the researchers' performance: 1) refereed journal articles and other research and development products/outputs; 2) competitive grants or external resource funds generated for research or development work; and 3) networking.

The guidelines in the conduct of researches and the parameters used for the evaluation of the researchers' performance are expected to further enhance staff performance and output. The new guideline also provides a good backing towards the promotion of the culture of research among the personnel of the institution that provides science and technology-based services.

For the harmonization of instructions and measures, supplemental Memorandum Orders are issued detailing the parameters and conditions that may be satisfied. In particular, these are: Memorandum Order Number 2012-245 or the "Reiteration of the Adoption of Workload System and Its Harmonization with the New Performance Management System (PMS)"; Memorandum Order Number 2012-254 or the "Clarification/Additional Guidelines on Memorandum Order No. 2012-245". The former memorandum summarizes the workload and equivalent PMS output and rating of every position under the Research Sector while the latter memorandum emphasizes that "a minimum output of one publication per PMS period of 1 year is required for all Senior Research Staff”.

A researcher is considered a senior research staff if he/she occupies any of the following Science Research Specialist (SRS) positions: SRS I, SRS II, Senior SRS, Supervising SRS, and Chief SRS.

The new policy is expected to improve the dissemination of research-based knowledge to the public and the clienteles. The PhilRice consider the policy reform as a good public administrative measure. First, it upholds the principle of transparency through the sharing of research findings to the local and international forums; and in making the results of locally-and internationally-funded projects and studies accessible to the public. Finally, it fosters accountability among the researchers and the management when it comes to sharing of reliable 
information. According to Gabriel and Ong (2018), the interplay between transparency and accountability encourages citizens' engagement in government activities. It also enhances trust and confidence of people to the government [9].

Nonetheless, in spite the good intentions of the new policy, efforts must be done to ensure its proper implementation. Therefore, the management should make sure that system is in place to disseminate the information and to promote compliance among employees.

The new research policy at PhilRice encouraged the researchers of this study to determine the awareness and perception of the PhilRice researchers on the new policy provisions.

The paradigm used in the study is presented in Figure 1.

\subsection{Research Paradigm}

The study adopted the systems approach or the Input-Process-Output framework. Enumerated in the Input box are the administrative orders, memorandum orders, and policy on Performance Management issued and implemented in the PhilRice. Simply put, the leftmost box represents the legal bases that guide the researchers in framing the discussion and in analyzing the data collected. Meanwhile, the center or Process box represents the processes undertaken to collect and analyze the data collected to come up with the items listed in the rightmost box stating the perceived benefits of publication. The entire process is linked by a feedback loop which means that the process is cyclical and that feedback mechanism is part of every step. The last step is the reechoing of findings to contribute to the improvement of the policy in place.

\subsection{Statement of the Problem}

The study seeks to determine the level of awareness and the perceptions of PhilRice researchers on the implementation of the policy in publication. Specifically, it attempts to answer the following questions:

1) How may the demographic profile of the respondents is described in terms of:

a) Sex

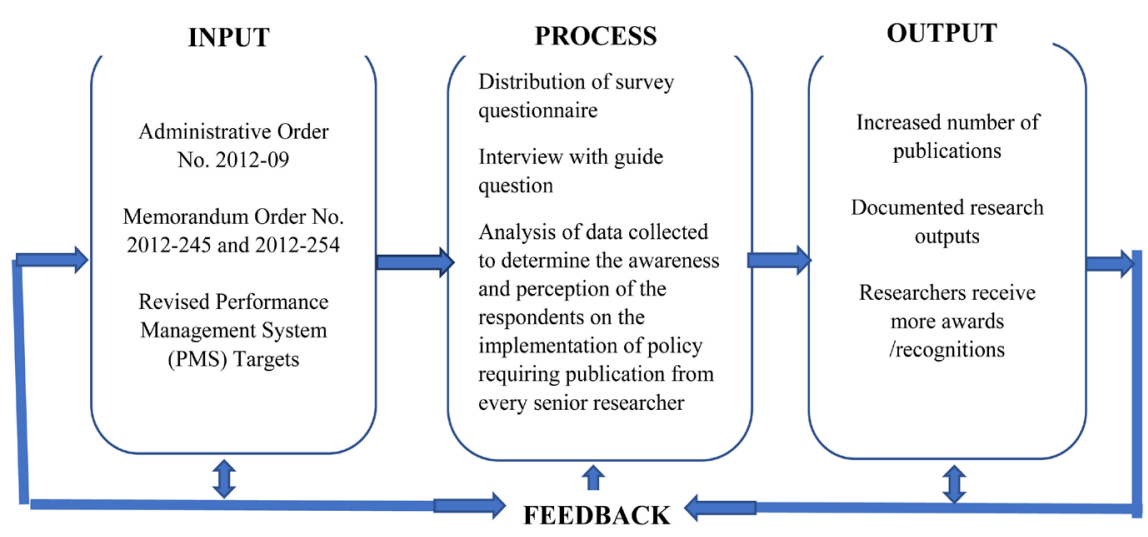

Figure 1. Paradigm of the study. 
b) Age

c) Civil Status

d) Educational Attainment

e) Position

f) Number of years in service

2) How may the perception of the respondents on the new policy be described based on:

a) Awareness

b) Source of information

c) Support extended to the management

d) Number and type of research published

e) Suggestions for the successful implementation of the policy

3) What recommendations may be offered based on the findings of the study?

\subsection{Hypotheses of the Study}

Based on data collected and analyzed, the researchers will prove or disprove the following hypotheses:

Ho $=$ The PhilRice Researchers are not aware of the policy reform and its provisions.

$\mathrm{H} 1=$ The PhilRice Researchers are aware of the policy reform and its provisions.

\subsection{Scope and Limitation}

The study is limited to the PhilRice researchers of the Central Experiment Station in Science City of Muñoz, Nueva Ecija, Philippines. It is the station with the greatest number of staff who renders science and technology-based services.

The study focuses on the PhilRice researchers' awareness on the policy and their perception as to the appropriateness of the policy reform. Included as well, is their awareness on the policy that all Senior Research Staff are aware of the minimum output of at least 1 publication per PMS period.

\section{Methods}

\subsection{Research Design}

The study used the descriptive type of quantitative research. The study described and measured the awareness and perception of the PhilRice Researchers on the new research policy being implemented in the institution. It also analyzed the constraints in the implementation of the policy. Two instruments were used in the study namely; questionnaire and unstructured interview guide.

\subsection{Research Locale}

The study was conducted in the Central Experiment Station of Science City of Muñoz, Nueva Ecija, Philippines (shown on Figure 2). It is 151 kilometers away from Metro Manila and is situated at $15^{\circ} 43^{\prime} 46.2^{\prime \prime N} 120^{\circ} 52^{\prime} 22.3^{\prime \prime E}$. 


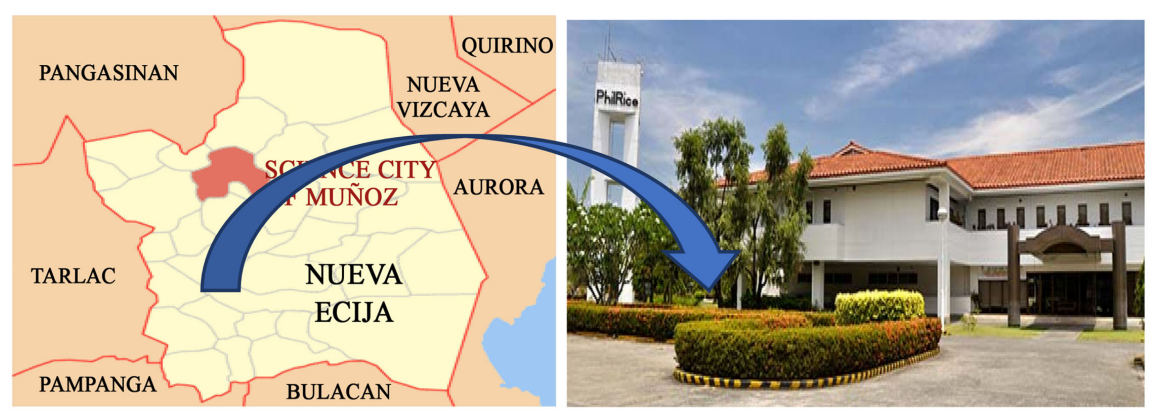

Figure 2. Map of Muñoz, Nueva Ecija Source: Gonzales, 2008 [10].

\subsection{Sample Population and Sampling Procedure}

The researchers secured written permission from the management and employees of PhilRice Head Office.A self-completion questionnaire was prepared solely for the purpose of the study. Since self-made questionnaire was used, pilot testing was conducted with other willing participants not included in the sample population. To measure the internal consistency or reliability of the instrument, the items were collected and subjected to Cronbach's alpha. Most of the questions with a coefficient of 0.7 to 0.9 were retained while, items with less than 0.6 a coefficient were deleted. Based on what was observed from the sample respondents, the questionnaire was restructured and field observation was scheduled.

The final questionnaire was divided into four parts. The first part consists of questions related to the respondents' demographic profile such as sex, age, civil status, educational attainment, position, years in service at PhilRice. The second part consists of questions about the respondents' awareness on the new policy (yes/no); sources of information (e-mail, memorandum, colleague, meetings); and the respondents' reasons for supporting the policy (7 items in checklist form and a space for additional information/observation). The third part is composed of questions that provide information on the number of staff with publication, the types of their publication (12-item checklist); problems encountered in complying with the policy; recognized publications of PhilRice Researchers (5 items in checklist form, namely; ISI Journals, Book and Book Chapter, Rice varieties, Non-ISI Journals, Patents, and Utility Models). In addition, a semi-structured interview guide was used to elicit more specific information regarding the topic.

Out of the sixty-six (66) total number of researchers in the PhilRice Central Experiment Station, 37 samples were chosen, given questionnaires, and interviewed. The samples were from the following divisions/offices: 1) Agronomy, Soils, and Plant Physiology Division (ASPPD); 2) Crop Protection Division (CPD); 3) Genetic Resources Division (GRD); 4) Plant Breeding and Biotechnology Division (PBBD); 5) Rice Chemistry and Food Science Division (RCFSD); 6) Rice Engineering and Mechanization Division (REMD); and 7) Socioeconomics Division (SED). 
Secondary data were also collected from the printed PhilRice Anniversary Souvenir Programs from year 2010 to 2018. Those who were conferred with Outstanding PhilRice Staff award, special awards, and those who were able to publish their researches in peer-reviewed journals were given due recognition every month of November.

The data gathered using the questionnaire were presented in tabular, graphical, and textual forms.

\section{Results and Discussions}

This part presents and interprets the data gathered from the respondents including the demographic profile; awareness and perception of the respondents on the new policy; and the number and type of research published by the PhilRice researchers.

\subsection{Demographic Profile of Respondents}

\subsubsection{Sex}

Of the 37 total respondents surveyed from the PhilRice Central Experiment Station in PhilRice, Muñoz, Nueva Ecija, 41\% $(\mathrm{n}=15)$ are male and 59\% $(\mathrm{n}=22)$ are female. Shown in Table 1 is the distribution of respondents based on sex to wit.

The data in the table above shows that more women agreed to be part of the study. Also, the data reflects the equal opportunity extended by the institution to both sexes, and the involvement of women in research. Meanwhile, the respondents' age distribution is presented in Table 2.

\subsubsection{Age}

Twenty-seven percent $(n=10)$ of the respondents are aged 31 to 40 ; forty-nine percent $(n=18)$ are within 41 to 50 years old; twenty-two percent $(n=8)$ are within 51 to 60 years old; and three percent $(n=11)$ are within 61 - 65 years old (Table 2). It implies that the organization has an aging population when it comes to the number of staff engaged in research.

Table 1. Distribution of respondents according to sex.

\begin{tabular}{ccc}
\hline Sex & Frequency & Percentage \\
Male & 15 & $41 \%$ \\
Female & 22 & $59 \%$ \\
\hline
\end{tabular}

Table 2. Distribution of respondents according to age.

\begin{tabular}{ccc}
\hline Age & Frequency & Percentage \\
\hline $31-40$ & 10 & $27 \%$ \\
$41-50$ & 18 & $49 \%$ \\
$51-60$ & 8 & $22 \%$ \\
$61-65$ & 11 & $3 \%$ \\
\hline
\end{tabular}


In a study on effects of aging on the PhilRice researchers' publication and citation pattern, Gingras et al. (2008) mentioned that researchers at 40 years of age start to rely on older literature and that their productivity also slows down. PhilRice researchers on their 50s are at the peak of their productivity while their average scientific impact is at its lowest. The data on the same study also showed that older professors who stay active in research are often able to keep high level of productivity until retirement. Gingras et al. (2008) also found out that the average scientific impact of professors decreases steadily from the beginning of their careers until their $50 \mathrm{~s}$, and then increases again after this period. Also, older professors tend to publish fewer first-authored papers and move closer to the end of the list of co-authors [11].

Meanwhile, Ueda and Ohzono (2013) work values vary depending on gender, marital status, and generation. Based on their findings, working persons between the ages of 20 and 50 demonstrate higher levels of accomplishment and better work values compared to those in their $30 \mathrm{~s}$ or $40 \mathrm{~s}$. On the other hand, those in their $20 \mathrm{~s}$ show higher levels of power and authority and inclination towards monetary rewards. In contrast, working persons in their $50 \mathrm{~s}$ have lower power and authority but higher levels of contribution and better work values [12]. However, some published researches disprove the statistical correlation between age and productivity/performance while others believe otherwise, that age and productivity are significantly correlated especially for jobs that require high physical strength or physical workload. That is, performance decreases as age increases [13].

Also, part of the demographic information collected is the civil status of respondents. The civil status of the respondents surveyed are enumerated and quantified in Table 3.

\subsubsection{Civil Status}

The respondents' civil status was also determined. Eighty four percent $(n=31)$ of the respondents are married while fourteen percent $(n=5)$ are single and three percent $(n=2)$ are widows.

Married people are assumed to be more responsible and cautious with their performance [14]. Nonetheless, their non-compliance with the office policies will somehow affect their employment status leading to possible non-provision of basic needs for their respective families.

In a study conducted by Ueda and Ohzono (2013), they found out that accomplishment, contribution, and power and authority are significantly higher

Table 3. Distribution of respondents according to civil status.

\begin{tabular}{ccc}
\hline Status & Frequency & Percentage \\
\hline Married & 31 & $84 \%$ \\
Single & 5 & $14 \%$ \\
Widow & 2 & $3 \%$ \\
\hline
\end{tabular}


for married working persons than for their unmarried counterparts. They added that married persons demonstrated higher levels of work values for monetary rewards were expected and understandable. They also argued that many married persons must provide financial support for their spouses and children. Therefore, they have greater interest in earning money to fulfill these obligations [12].

In terms of educational attainment, the respondents are segregated into graduates of either Bachelor's degree; Master of Science; Doctorate; and Post-doctorate. The educational attainment and the accompanying number and percentage of respondents are presented in Table 4.

\subsubsection{Educational Attainment}

The respondents who are mostly MS degree holders and above have been exposed to publication requirement, thesis or research writing before they graduated from their respective degrees. Thus, they do not consider the research and publication requirement for PhilRice staff as a problem.

\subsubsection{Position}

Using survey questionnaire, the respondents were asked to provide their positions or ranks in the institution. In the questionnaire, the respondents were asked to tick whether they are presently working as Science Research Specialist (SRS) I, SRS II, Senior SRS, Supervising SRS, and Chief SRS. From their responses, the following values, as shown on Figure 3 were arrived at:

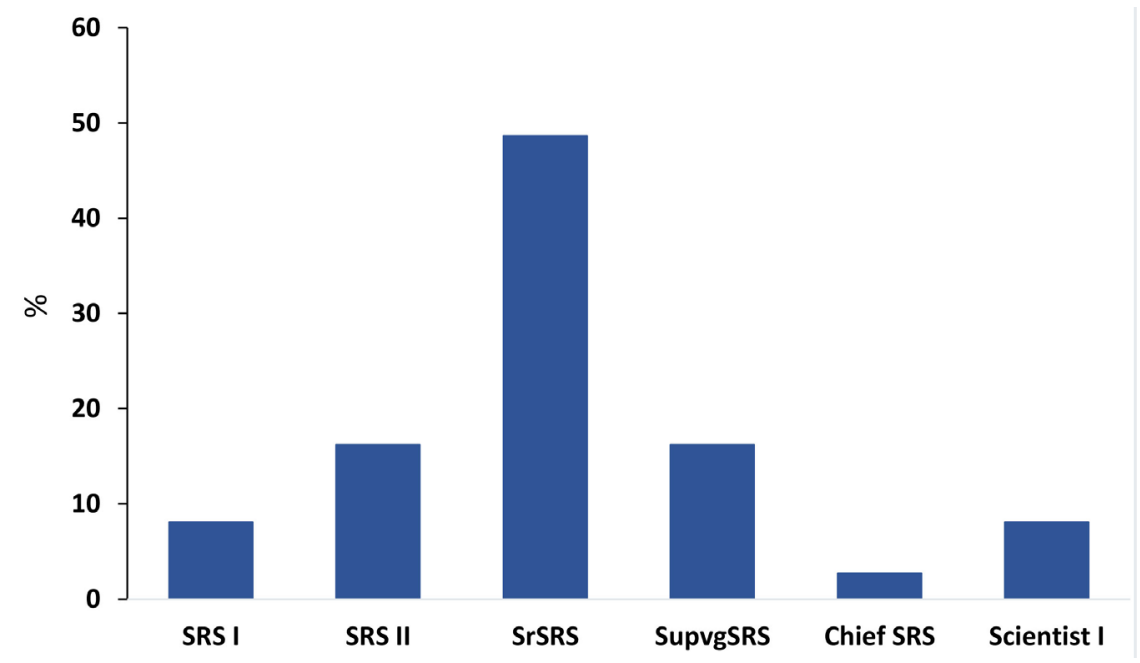

Figure 3. Distribution of respondents' positions in the institution.

Table 4. Distribution of the respondents' educational attainment.

\begin{tabular}{ccc}
\hline Educational Attainment & Frequency & Percentage \\
\hline Bachelor's Degree & 9 & $24 \%$ \\
Master of Science & 21 & $57 \%$ \\
Doctorate Degree & 5 & $14 \%$ \\
Post-Doctorate & 2 & $5 \%$ \\
\hline
\end{tabular}


Eight percent of the respondents $(\mathrm{n}=3)$ said that they are currently employed as Science Research Specialist (SRS) I while sixteen percent $(n=6)$ are SRS II and forty-nine percent $(n=18)$ are Senior SRS. Sixteen percent $(n=6)$ occupies the higher position as Supervising SRS; three percent $(\mathrm{n}=1)$ as Chief SRS; and eight percent $(n=3)$ as Scientist I. The data shows that most of the researcher respondents are hold high research positions at PhilRice. Also, attached to their position is the expectation that they will produce the bulk of researches for the institution.

\subsubsection{Years of Service at PhilRice}

The respondents are all permanent employees of PhilRice. To complete the information on the demographic profile of the respondents, they were asked to provide the number of years they are in service (from contractual status up to the time they were appointed to their current permanent positions). Their responses were tallied and presented in Table 5.

Five percent $(n=2)$ of them are already at PhilRice for less than 5 years. Eight percent have been working for $6-10$ years $(n=3)$ and $11-15$ years $(n=3)$ respectively, while $35 \%(n=13)$ have been in the institution for $16-20$ years. In addition, thirty percent $(n=11)$ are in service for $21-25$ years. Only fourteen percent of the staff surveyed $(n=5)$ have been in the institution for 26 - 30 years. The data reflects that many of the staff are already working in the institution as researchers, years before the implementation of the policy on publication on 2012. It also implies that notwithstanding the number of years in service, PhilRice researchers are required to undertake research activities and to publish their researches for the knowledge of other researchers and the public.

\subsection{Awareness and Perception}

The study sought to determine the awareness and perception of the PhilRice researchers particularly those engaged in research activities on the new policy.

\subsubsection{Awareness on the New Policy}

Out of the 37 staff surveyed, ninety seven percent $(\mathrm{n}=36)$ answered "yes" or that they are aware of the new policy on research and publication. Whereas, only three percent $(\mathrm{n}=1)$ said " $n o$ ". The respondent answered no because of zero

Table 5. Distribution of the respondents' years in service at PhilRice.

\begin{tabular}{ccc}
\hline Years in Service & Frequency & Percentage \\
\hline Less than 5 years & 2 & $5 \%$ \\
$6-10$ years & 3 & $8 \%$ \\
$11-15$ years & 3 & $8 \%$ \\
$16-20$ years & 13 & $35 \%$ \\
$21-25$ years & 11 & $30 \%$ \\
$26-30$ years & 5 & $14 \%$ \\
\hline
\end{tabular}


awareness on the policy but rather on because of lack of awareness on the extent of the implementation of the new policy. The data shows that the management has extended the necessary measures to disseminate the information prior to the full implementation of the policy reform.

\subsubsection{Source of Information on the New Policy}

The respondents who knew about the policy said that they learned about it through various channels. Forty-one percent $(n=15)$ said that they learned about the new policy when they received printed copy of the memorandum. Some of respondents mentioned that they received the memorandum stating the new policy through an e-mail from the management. Eleven percent $(n=4)$ said that they learned about the new policy when they attended a scheduled meeting. Five percent $(n=2)$ said that they heard about the new policy from a colleague. Meanwhile, majority of the respondents $(49 \%$ or $n=18)$ affirmed that they developed awareness about the policy through all the mentioned modalities: electronically (e-mail), manually (sent in printed copy), and even through words of mouth (from a colleague).

The results suggest that the institution employed various methods in disseminating information prior to the full implementation of the policy reform.

\subsubsection{Support to the Policy}

Even though there was one unaware respondent, all of them $(n=37)$ supports the policy. Various reasons emerged as to why they support the implementation of the policy reform in the institution. Ninety-five percent $(n=35)$ mentioned that they believe that through the policy, they will be able to share the results of their experiment to the clients/farmers/stakeholders. Sixty-eight percent $(n=25)$ said that publication is a scientific and verifiable basis of performance and accomplishments. Sixty-five percent $(n=24)$ believe that the findings of the research study will be protected once published. Meanwhile, it can be gleaned from the table that $3 \%$ of the respondents mentioned six other reasons aside from those listed in the questionnaire.

Three percent believed that the policy strengthens the institutional policy that it is a scientific obligation of every researcher to share their research results to the public. Additional three percent of the respondents believed that they support the policy because they want to become civil servant scientists.

The items presented in Table 6 shows that the respondents understand the benefits of having a publication. It can also be gleaned from the table that only 38 percent mentioned that they support the implementation of the policy because it is required by the institution. During the interview, many of them thought that there is more to it than additional workload. For them, it is a strategy implemented by the management to encourage them to think outside of the box and to contribute to the knowledge in the field.

Bautista et al. (2012) emphasized that a research paper published in peer-reviewed journal provides satisfaction especially when it is interesting, 
Table 6. Reasons for supporting the policy of publication.

\begin{tabular}{ll}
\hline \multicolumn{1}{c}{ Reasons for support } & $\%$ \\
\hline To share the results of my experiments to the clients /farmers/stakeholders & 95 \\
It is the scientific and verifiable basis of my performances and accomplishments & 68 \\
The findings of my research study will be protected once published & 65 \\
I will receive a reward/incentive due to publication & 41 \\
Publication under my name is an additional credit to my resume' & 51 \\
I must support since it is required by the Institute & 38 \\
Publication is a widely known required output of any researcher & 54 \\
Other reasons specified by the respondents: & 3 \\
It is a scientific obligation of every researcher to share research results & 3 \\
To become civil servant scientist & 3 \\
Adds on credentials and integrity as a researcher & 3 \\
Gives fulfillment as a researcher & 3 \\
Requirement under the SCS program & 3 \\
\hline
\end{tabular}

novel or offers fresh insight. Publication especially in peer-reviewed journals also raises the stature of the researcher as scientist and increases the likelihood of getting scholarship grants, research sponsorships, and even a job offer [2].Arnake (2015) also explained that implementing research and publishing results is crucial for a career in sciences [7]. Doing research is only half of the picture. The true test of determination and quality of the paper is when it gets accepted and published in an international journal accessible to other researchers. The production of knowledge through the conduct of scientific researches and the accessibility of knowledge through publication add to the databank of knowledge which can be used as reference and even replicated using other variables and settings. Table 7 shows the percentage of PhilRice researchers with publication.

\subsubsection{Percentage of PhilRice Researchers with Publication}

In terms of the number of publications, $92 \%(\mathrm{n}=34)$ of the respondents said that they have publications in various peer-reviewed journals. Only $8 \%(n=3)$ tick "no" or mentioned that they do not have publication at the time of data collection. It only proves that even before the implementation of the new policy, the PhilRice staff have been generating researches which are credited under their names and in the institution. Those with publication were asked about the type of publication they have. Their responses were analyzed and tabulated (Table 8).

\subsubsection{Types of Publications}

Since the institution offers various services, the PhilRice researchers also do research in various fields and disciplines. Thus, they are able to generate outputs suited for different platforms and genre as reflected in Table 8. 
Table 7. Percentage distribution of PhilRice researchers with publication.

\begin{tabular}{cc}
\hline Presence of Publication & $\%$ \\
\hline With publication & 92 \\
Without publication & 8 \\
\hline
\end{tabular}

Table 8. Type of publications produced by respondents.

\begin{tabular}{cc}
\hline Type of publication & $\%$ \\
\hline Scientific, technical or policy paper & 78 \\
Research notes/policy briefs & 16 \\
Technical bulletin & 14 \\
Book Chapter & 27 \\
Book/monograph & 22 \\
Technical editor of book & 11 \\
Handouts/leaflets & 16 \\
Patent & 8 \\
Utility models & 5 \\
Industrial design & 0 \\
Developed/co-developed varieties & 14 \\
Extension model & 3 \\
\hline
\end{tabular}

Seventy-eight percent $(n=29)$ or majority of the respondents have generated scientific, technical or policy papers. Twenty-seven percent $(n=10)$ have contributed or published book chapters; while twenty-two percent $(n=8)$ have published books/monographs among others. The data presented on the table reflects that most of the respondents prefer doing scientific, technical, or policy papers. The observation is congruent with the thrust of the institution to provide scientific knowledge which is accessible to the community. Commonly, in the form of research articles published in peer-reviewed research journals and government-generated technical or policy papers.

\subsubsection{Problems Encountered}

Although majority of the researchers are able to comply with the publication output requirement, they also encountered problems including the following: too many workloads/assignments $(26 \%$ or $70 \%)$, editors/reviewers do not respond within the period needed ( $20 \%$ or $54 \%$ ), too many official travels that results to insufficiency of time to write ( $5 \%$ or $14 \%$ ), lack or insufficient data because the study is not yet finished (4\% or $11 \%$ ), and no budget for publication fees $(4 \%$ or $11 \%)$.

The lists of common problems encountered by the respondents in complying with the policy are presented in Table 9. The additional observations collected from the open-ended questions in the questionnaire and during the interview are also enumerated with accompanying percentage. 
Table 9. Problems encountered in complying with the policy.

\begin{tabular}{|c|c|}
\hline Problems encountered & $\%$ \\
\hline Editors/reviewers do not respond within the period needed & 54 \\
\hline Lack or insufficient data because the study is not yet finished & 11 \\
\hline Too many workloads/assignments & 70 \\
\hline Too many official travels & 14 \\
\hline No budget for publication fees & 11 \\
\hline \multicolumn{2}{|l|}{ Other reasons specified by the respondents: } \\
\hline Review process and acceptance is beyond my control & 3 \\
\hline $\begin{array}{l}\text { Rejection of submitted work, thus, revision is needed, } \\
\text { and another round of submission process needs to be undertaken }\end{array}$ & 3 \\
\hline Cannot return edited paper due to time constraint & 3 \\
\hline Difficult to publish in high impact journals, inaccessibility of online journals & 3 \\
\hline $\begin{array}{l}\text { Difficult to adopt the workload system; social responsibility } \\
\text { by ensuring continuity of employment of their trusted workers }\end{array}$ & 3 \\
\hline $\begin{array}{l}\text { Lack of knowledge of Financial Management } \\
\text { Division on the process of scientific publications }\end{array}$ & 3 \\
\hline Need exclusive time for writing like writing retreat & 3 \\
\hline
\end{tabular}

Based on their responses, the personnel believe that what hinders their compliance on the policy are somehow personal or related to workload and performance of their official functions. This implies that in order to finish a paper or to comply with the requirement, the employee-researchers must exert extra effort and find time to do the writing, data collection, and revision of the paper. These processes are more important if they want the paper to pass the standards of international and peer-reviewed journals.

\subsubsection{Suggested Amendments for the Improvement of the Policy}

When asked if they are in favor of amending the policy, $92 \%$ of the respondents affirmed that they support the policy in spite the challenges they encountered. The suggestions of the respondents and their corresponding percentage are reflected in Table 10.

Among the policy revisions suggested by the respondents are: 1) extension of required period of publication say, every after 2 years $(70 \%) ; 2$ ) lessen the number of required publication per year $(27 \%) ; 3)$ increase in the equivalent points set (22\%); and 4) making publication not compulsory (14\%).

There are also respondents who provided additional suggestions to make the policy more realizable. In fact, aside from choosing from among the options listed in the survey questionnaire, they also wrote down additional suggestions on the space provided in the survey questionnaire (shown in Table 10). Some information are collected from during the interview.

Bautista et al. (2012) claimed that researchers in the Philippines do not solely 
Table 10. Suggested amendments for the improvement of the policy.

\begin{tabular}{|c|c|}
\hline Suggested amendments & $\%$ \\
\hline It should not be required & 14 \\
\hline Reduce the required number of publications per year & 27 \\
\hline Extend the required period of publication (example every after two years) & 70 \\
\hline Increase the equivalent points set & 22 \\
\hline \multicolumn{2}{|l|}{ Decrease the equivalent points set } \\
\hline \multicolumn{2}{|l|}{ Other suggestions specified by the respondents: } \\
\hline Implement writeshop regularly where staff can focus I writing their & \\
\hline $\begin{array}{l}\text { publication in a separate venue outside PhilRice and require solid } \\
\text { tangible output after just like annual report writeshop }\end{array}$ & 3 \\
\hline $\begin{array}{l}\text { Consider milestones, it maybe helpful if researchers will be given time } \\
\text { to leave office for a while to write }\end{array}$ & 3 \\
\hline $\begin{array}{l}\text { That all approved studies should, at least, have a scientifically } \\
\text { publishable output at the end of its period }\end{array}$ & 3 \\
\hline $\begin{array}{l}\text { It is difficult to produce paper per year and one-year results are } \\
\text { not enough to establish a good conclusion; acknowledge other } \\
\text { outputs aside from paper publication }\end{array}$ & 3 \\
\hline $\begin{array}{l}\text { Please give credit to varieties developed; it takes years and huge } \\
\text { amount of budget to develop varieties }\end{array}$ & 3 \\
\hline Increase incentive & 3 \\
\hline $\begin{array}{l}\text { Posters should be considered publication; a staff should look the data to } \\
\text { assess if those are publishable; the group should be actively } \\
\text { prepare what is needed to be done }\end{array}$ & 3 \\
\hline Review value of patent in relation to publication & 3 \\
\hline Clarify the publication fee support as charges now are too high & 3 \\
\hline
\end{tabular}

conduct research but also have other duties and responsibilities such as administrators, heads, members of committees, professors, etc [2]. In a study conducted by Pittman et al. (2013) on "Barriers and facilitators to scientific writing among applied epidemiologists", they reported that most respondents (80\%) expressed a desire to publish; however, only $59 \%$ of them had published in a peer-reviewed journal. Time (68\%) was also identified as the greatest barrier to writing and publishing [15].

Other major barriers found in their study were lack of encouragement or support (33\%) within the public health agency and agency clearance processes (32\%). Furthermore, the authors reported that assistance with journal selection (62\%), technical writing skills (60\%), and manuscript formatting (57\%) were listed as the most needed trainings.

In the study of Calma (2013) on "Challenges in preparing academic staff for research training and supervision in the Philippines", the author reported that academic staff had difficulty in doing research because of too much workload in teaching [13]. In a study on "Perceptions and the implementation of Continuing Professional Development through publication among English Teachers", Ka- 
sprabowo et al. (2018), mentioned that English Teachers had positive perceptions towards the implementation of Continuing Professional Development scheme through publication. In practice, however, only few teachers wrote or published their works because of limited time to write, lack of training on writing, and other responsibilities assigned to them [16].

\subsubsection{Recognized Publications of PhilRice Researchers (2010-2018)}

Shown in Figure 4 that follows is the graphical representation of the publications of the PhilRice Researchers plotted in such a way that illustrates the number of researches published from year 2010-2018. The data is based on the observed frequency of the collected responses backed by the information reflected on the 2010-2018 PhilRice Anniversary Souvenir Programs circulated to all staff wherein the accomplishments of staffers are being listed and recognized. The list of recognized publication of PhilRice researchers are illustrated in Figure 4.

It is evident in the figure above that the strict implementation of the policy on publication contributed to the gradual increase in the number of documented outputs of PhilRice researchers. Particularly those published in ISI and non-ISI journals, books and book chapters, and registered patents and utility models. The comparison is generated out of the number of researches and publications generated prior to and after the implementation of the policy in 2012.

\section{Conclusions and Recommendations}

The findings of the study support the alternative hypothesis that the PhilRice researchers are aware of the policy on research and publication. Having understood the benefits of doing research and publishing the same in peer-reviewed journals made the respondents more supportive of the new policy. Consequently, they developed a positive impression towards research. The respondents felt that the management introduced the policy not to give them additional workload but to encourage them to think outside of the box. It is noteworthy that

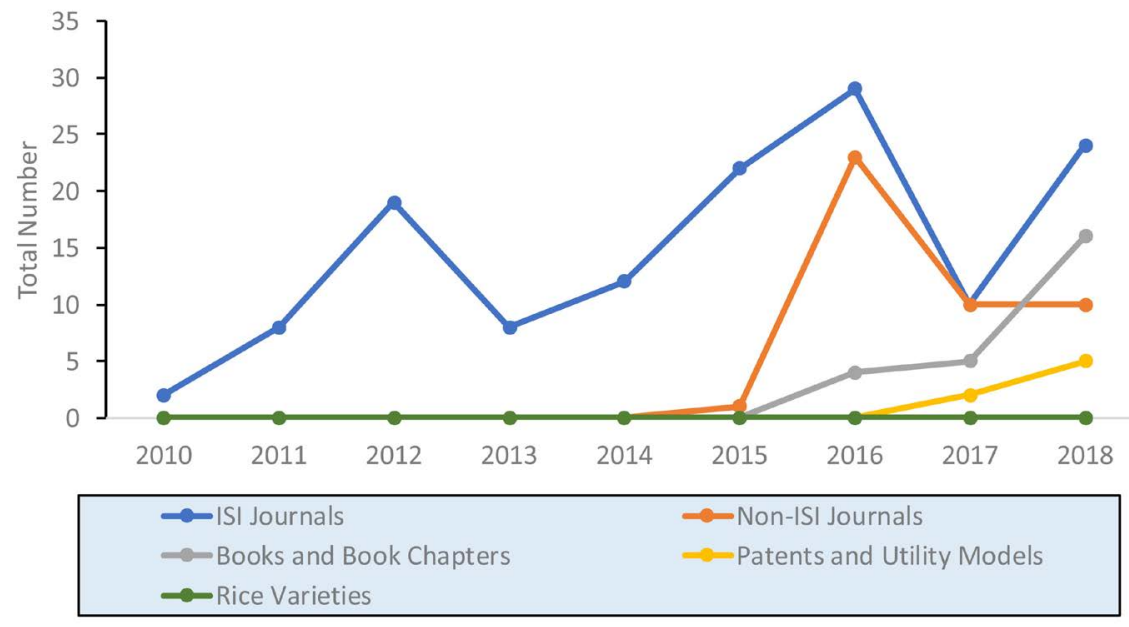

Figure 4. Recognized publications of PhilRice researchers (from 2010 to 2018). 
the management of PhilRice utilized various platforms to ensure the widest dissemination of information and to promote common knowledge about the new policy. While the PhilRice researchers support the implementation of the policy on research and publication, they believe that what hinders their compliance is rather personal (time management, writing requirements) and related to their functions (difficulty balancing workload). In terms of output or the number of scholarly papers published, it can be noted that even before the policy was implemented, the PhilRice researchers are already producing publishable researches as part of the scopes of their jobs. For some, research gives them fulfillment especially when the findings benefit the institution and the public as co-producers of knowledge.

As a research institution that is expected to generate science and technology-based information, PhilRice imparts to its researchers the idea that researches are conducted for public use and benefit. As the findings suggest, the more the personnel are aware of the conditionalities of the policy and the processes involved in research writing, the more they are likely to comply with the requirements. Researchers are conducted and sometimes funded, to develop knowledge that will improve current technologies. Research is not just about collecting information but also sharing the result to the clients and stakeholders (transparency) and taking responsibility for the outcomes and the manner by which the information was made public (accountability).

For the policy to be fully-realized, the suggestions of both the management and the employees must be collected, consolidated, and discussed. The management may also consider the holding of regular orientations, seminars, and trainings, or even mentoring to further promote the culture of research in the institution.

\section{Conflicts of Interest}

The authors declare no conflicts of interest regarding the publication of this paper.

\section{References}

[1] Andrews, R. and Esteve, M. (2015) Still Like Ships That Pass in the Night? The Relationship between Public Administration and Management Studies. International Public Management Journal, 18, 31-60.

[2] Bautista, O.K., Rosario, T.L. and Bautista, R.K. (2012) Technical Writing for Publication in Journals and for Presentation. University of the Philippines Los Baños, College, Laguna, $218 \mathrm{p}$.

[3] The Merriam Webster Dictionary App (2017)

[4] Cambridge Dictionary (2018) https://dictionary.cambridge.org/

[5] Student Learning Development (SDL) (2009) Writing for Science. Student Learning Development, University of Leicester, Leicester, 5 p.

https://www.le.ac.uk/succeedinyourstudies

[6] Rawat, S. and Meena, S. (2014) Publish or Perish: Where Are We Heading? Journal 
of Research in Medical Sciences, 19, 87-89.

[7] Asnake, M. (2015) The Importance of Scientific Publication in the Development of Public Health. Ciência \& Saúde Coletiva, 20, 1972-1973.

https://doi.org/10.1590/1413-81232015207.08562015

[8] https://www.philrice.gov.ph

[9] Gabriel, A.G. and Ong, D.U. (2018) Linking Transparency and Accountability to Local Legislative Performance in the Province of Nueva Ecija in the Philippines. Journal of Public Administration and Governance, 8, 384-396.

[10] Gonzales, M. (2018). Map of Nueva Ecija with Muñoz Highlighted. https://commons.wikimedia.org/w/index.php?curid=5534662

[11] Gingras, Y., Lariviere, V., Macaluso, B. and Robitaille, J.P. (2008) The Effects of Aging on Researchers' Publication and Citation Patterns. PLoS ONE, 3, e4048. https://doi.org/10.1371/journal.pone.0004048

[12] Ueda, Y. and Ohzono, Y. (2013) Differences in Work Values by Gender, Marital, Status, and Generation: An Analysis of Data Collected from "Working Person Survey 2010". International Journal of Human Resource Studies, 3, 28-41.

[13] Health and Safety Executive (HSE) (2011) An Update of the Literature on Age and Employment. Health and Safety Executive, Harpur Hill, Buxton, Derbyshire, 79 p.

[14] Calma, A. (2014) Challenges in Preparing Academic Staff for Research Training and Supervision. International Journal of Educational Management, 28, 705-715. https://doi.org/10.1108/IJEM-06-2013-0092

[15] Pittman, J., Stahre, M., Tomedi, L. and Wurster, J. (2013) Barriers and Facilitators to Scientific Writing among Applied Epidemiologists. Journal of Public Health Management and Practice, 23, 291-294. https://doi.org/10.1097/PHH.0000000000000433

[16] Kasprabowo, T., Sofwan, A. and Bharati, D. (2018) Perceptions and the Implementation of Continuing Professional Development through Publication among English Teachers. English Education Journal, 8, 123-129. 